\title{
A Choice Based Experiment of Community Supported Agriculture (CSA): A Valuation of Attributes
}

\author{
Qiushuo Yu, Ben Campbell, Yizao Liu, and Jiff Martin
}

\begin{abstract}
Community-supported agriculture (CSA) operators are becoming more innovative in their efforts to attract consumers to become CSA shareholders. Therefore, CSA operators must understand which attributes consumers value. Using an online survey of Connecticut consumers in conjunction with a choice experiment, we evaluate consumer preference and willingness to pay for various attributes, including risk mitigation. We find younger consumers are more likely to prefer CSAs with organic products, while a greater diversity of products in the CSA share will increase preference for a CSA for some consumers. Further, we find that consumers with and without CSA experience value the risk-mitigation attribute.
\end{abstract}

Key Words: community-supported agriculture, consumer preference, willingness to pay

JEL Code: Q13

Community-supported agriculture (CSA) is "a system in which a farm operation is supported by shareholders within the community who share both the benefits and risks of food production." (Wilkinson 2001). CSAs attempt to directly link local residents and nearby farmers, eliminating "the middleman" and potentially increasing benefits to both farmers and consumers. In a CSA, the farm business grows food for a group of consumers, usually called "shareholders," "members," or "subscribers," who commit at the beginning of each year to purchase a portion of the farm's crop. The shareholders thus directly support the farm and receive a product, generally produce, weekly or monthly. Unlike other direct retail formats such as a farm stand or farmers market, CSA operators receive an initial cash investment to finance their

Qiushuo Yu Graduate Research Assistant, Department of Agricultural and Resource Economics, University of Connecticut. Ben Campbell Assistant Professor, Department of Agricultural and Applied Economics, University of Georgia. Yizao Liu Assistant Professor, Department of Agricultural Economics, Sociology, and Education, The Pennsylvania State University. Jiff Martin Associate Extension Educator, Department of Extension, University of Connecticut. Correspondence: Ben Campbell - Assistant Professor - Department of Agricultural and Applied Economics - University of Georgia = 314A Conner Hall - Athens - GA 30602 - Phone: (706) 542-0852 - Email: bencamp@uga.edu Funding has been provided by the Specialty Crop Block Grant Program of the Agricultural Marketing Service, U.S. Department of Agriculture, awarded and administered by the Connecticut Department of Agriculture. The views expressed are the authors' and do not necessarily represent the policies or views of any sponsoring agencies.

Agricultural and Resource Economics Review 48/1 (April 2019) 1-20

(C) The Author(s) 2018. This is an Open Access article, distributed under the terms of the Creative

Commons Attribution licence (http://creativecommons.org/licenses/by/4.0/), which permits unrestricted re-use, distribution, and reproduction in any medium, provided the original work is 
operation; thereby, both parties jointly share the benefits and risks of the production season.

The first semblance of the CSA model as we know it today came from the "teikei" movement in Japan during the 1960s; the first CSAs appeared in the United States during the mid-1980s (Strochlic and Shelley 2004; Kelley, Kime, and Harper 2013). Since the first CSA farms were established, CSA numbers rose to between 4000-6500 CSA farms in 2012-2013 (McFadden 2012; Ernst 2013). The pioneering CSAs were philosophically oriented toward shared risk and collective responsibility. Today, there is a wide variety across CSAs in terms of structure, shareholder participation, and distribution method. As the number of CSAs increases, some CSAs are struggling to price their shares in a way to support livable incomes for farmers and economic viability for farm businesses (Lizio and Lass 2005).

Local food sales in 2012 were estimated at $\$ 6.1$ billion, which was an increase of 27 percent from 2008 (Low and Vogel 2011; Low et al. 2015). As noted by Low and Vogel (2011), CSAs have become an important marketing channel for local food. Given the trend of CSAs toward a more viable business format and the increasing awareness of local food, it is essential to understand how consumers value the varying attributes that are typically offered by a CSA.

Brown and Miller (2008) provide an in-depth review of the consumer and producer impacts of CSAs. However, we provide a brief discussion of relevant CSA studies here. There have been several studies examining the consumer side of participating in a CSA. Conner (2003) found that two CSAs in their New York study area allowed shareholders to save money on organic produce when compared to local retail outlets' lowest-priced organic produce. As noted by Cooley and Lass (1998), shareholders experienced a cost savings of 60-150 percent of share prices based on retail prices for organic produce. Furthermore, shareholders who are vegetarian, female, and older are predictors of a CSA shareholder being satisfied with their share (Lang 2005), while consumer perception of price, productivity shifters, consumer beliefs and awareness affect the probability of membership in a CSA (Kolodinsky and Pelch 1997). CSA shareholders believe membership leads to eating more, fresher, and a greater variety of, vegetables; shopping less; and adopting healthier eating habits (Ostrom 2007). The motives of consumers within the Ostrom (2007) study align with motives of consumers purchasing "local" food, notably a perceived increase in quality and freshness, while also supporting the local economy (Onozaka, Nurse, and McFadden 2010). Furthermore, continued CSA participation "supports basic psychological needs for autonomy, competency, and relatedness." (Zepeda, Reznickova, and Russell 2013)

With respect to the producer side, only about 46 percent of farmers who responded to the 2001 national CSA survey were satisfied with their ability to cover operating costs, although 74 percent believed that their CSA operation had improved this ability (Lass et al., 2003). However, CSA farmers in Minnesota and Wisconsin indicated that they did not believe they earned 
an adequate return from their CSA operation (Ostrom 2007). Sproul and Kropp (2015) examine contract pricing and develop a series of propositions to help understand pricing across contract types. Sproul, Kropp, and Barr (2015) examine pricing for risk-mitigating shares (i.e., weight vs. yield shares) and find farmer-to-shareholder risk transfer as having a significant effect on share price.

Most similar to our study is the work of Connolly and Klaiber (2014), who use an hedonic model to value varying attributes (i.e., product offerings, contract length, number of pick-up days, and production techniques) within CSAs. Their findings indicate that consumers' willingness to pay (WTP) is higher for more weeks of participation, off-farm pick-up, and organic production (Connolly and Klaiber 2014).

Our study builds on the Connolly and Klaiber (2014) study in several ways. First, our primary objective was to use a choice experiment and latent class analysis to better understand consumer preference and WTP for a variety of CSA attributes. Of particular interest, we include a risk-mitigating attribute that would allow shareholders to recoup some of their costs in case the producer failed to deliver product, such as during a bad crop year or due to low quality. Sproul, Kropp, and Barr (2015) were the first to discuss riskmitigating shares and note that CSAs in their sample offered different types of shares with some (i.e., weighted) shares eliminating shareholder risk, while other share types (i.e., yield) do not eliminate shareholder risk. Considering producers have been shown to feel a responsibility to meet consumer expectations with respect to supply (Lea et al., 2006), inferior quality may be introduced into the supply to meet demand. For instance, Sproul, Kropp, and Barr (2015) note that weighted shares guarantee some weight of product at pick-up. This may lead to low-quality product being used to meet weight requirements, or create issues when there is no product available. Low quality and the potential for lack of product (e.g., as a result of bad weather) have been found to negatively impact the decision to join or rejoin a CSA (Cooley and Lass 1998; Goland 2002; Perez, Allen, and Brown 2003; Lea et al. 2006), thereby, finding risk-mitigating mechanisms may encourage CSA membership or increase retention. This is especially true given O'Hara and Stagl's (2001) finding that sharing risk with the farmer is significantly lower in importance compared to other reasons for joining a CSA. If producers can build in mechanisms (e.g., money-back guarantees or discounts) into their CSA to alleviate the need for low-quality product introductions or eliminate some of the fear associated with paying money for no product in return, then there is potential to increase CSA producer returns.

Though a money-back guarantee and discount are not common in CSAs today, these mechanisms could offer a means of differentiation for some CSAs, especially given that many markets may be reaching a saturation point. We hypothesize that there will be multiple latent classes with a subset of the classes valuing the risk attribute. Multiple latent classes are anticipated because we suspect there is heterogeneity of preferences across attributes 
such that any recommendations that do not take into account this heterogeneity may create inaccurate recommendations. With respect to the risk attribute, we hypothesize that some consumers will prefer the money back option while others will prefer the discount option.

A secondary objective is that via the latent class analysis we can identify demographics associated with the latent classes that can be used to inform CSAs in their decision making, given preference for attributes can be linked with significant demographics. Of interest within the probability model is an experience attribute (current CSA users, currently participating and planning to continue in the future; not currently participating but have in the past and plan to in the future; consumers who have never participated but have an interest in participating in the future). We hypothesize that significant demographics will be identified within the latent classes, thereby allowing meaningful recommendations to be made to CSAs.

\section{Data and Methodology}

To better understand which attributes consumers value in a CSA, we initiated an online study during fall 2013. Respondents were comprised of Connecticut consumers within the Global Market Insite (GMI), Inc. database panel who were 18 years or older. GMI allows the researcher to set parameters on demographics (and other factors if needed) and then samples from panelists who fit the desired criteria. Panelists who fit the survey criteria were emailed an invitation and link to the survey. Those agreeing to participate were directed to the survey. With respect to parameters for this study, only Connecticut (CT) residents were sampled, but panelists from across all demographic backgrounds were surveyed.

We focused on Connecticut consumers who would most likely have an interest in being a part of a CSA. Connecticut was chosen for a variety of reasons, notably that the funding agency was interested in Connecticut. However, given the stated interest of the State of Connecticut Council for Agricultural Development in increasing local food consumption, CSAs can help the state reach its goal of raising local food expenditures to at or above 5 percent of total food expenditures by 2020 (Connecticut Governor's Council for Agricultural Development 2016). Furthermore, as of 2012 Connecticut had approximately 100 CSAs operating within the state (University of Connecticut Cooperative Extension 2012). Based on counts by Localharvest. org, Connecticut has the fifth highest concentration of CSAs within the 12 Northeastern states (including the District of Columbia) with an average of one CSA for every 27,493 people (LocalHarvest, Inc. 2016).

Of the 1,348 consumers who completed the survey (91 percent completion rate), 589 indicated that they either had been or were currently participating in a CSA or had an interest in participating in the future. Respondents indicating they had never participated and did not have an interest in participating were not given the CSA choice experiment and therefore were 
eliminated from the analysis. The descriptive statistics associated with the total sample and those respondents who completed the CSA experiment can be found in Table 1. Notably, the main difference between the total sample and the CSA experiment sample was that higher incomes were associated with the CSA experiment group.

To assess representativeness of the of the CSA experiment sample to current and potential CSA participants, we would need to know the exact demographic characteristics (e.g., exact percentage of females interested in joining a CSA) associated with these groups. We can attempt to assess representativeness by comparing our sample to previous study findings. Demographics of those

Table 1. Demographics of the Sample

\begin{tabular}{|c|c|c|c|c|}
\hline & \multicolumn{2}{|c|}{$\begin{array}{l}\text { Sample in Choice } \\
\text { Experiment }\end{array}$} & \multicolumn{2}{|c|}{$\begin{array}{l}\text { Total Sample } \\
\text { Surveyed }\end{array}$} \\
\hline & Mean & $\begin{array}{l}\text { Standard } \\
\text { Deviation }\end{array}$ & Mean & $\begin{array}{l}\text { Standard } \\
\text { Deviation }\end{array}$ \\
\hline Median Age (years) ${ }^{a}$ & 48 & - & 52 & - \\
\hline \multicolumn{5}{|l|}{ Ethnicity } \\
\hline Caucasian & $88 \%$ & $33 \%$ & $89 \%$ & $31 \%$ \\
\hline African American & $4 \%$ & $20 \%$ & $4 \%$ & $14 \%$ \\
\hline Other ethnicity & $8 \%$ & $28 \%$ & $8 \%$ & $26 \%$ \\
\hline Number people in household & 2.7 & 1.3 & 2.5 & 1.3 \\
\hline Median household income $^{a}$ & $\$ 85,000$ & - & $\$ 75,000$ & - \\
\hline Gender $(1=$ male $)$ & $34 \%$ & $47 \%$ & $37 \%$ & $48 \%$ \\
\hline Body mass index (BMI) & 27.5 & 5.4 & 28.2 & 6.2 \\
\hline Food neophobia scale & 26.2 & 10.5 & 28.8 & 10.5 \\
\hline \multicolumn{5}{|l|}{ CSA Experience } \\
\hline Never participated, not interested & $0 \%$ & - & $56 \%$ & $50 \%$ \\
\hline Never participated, but interested & $82 \%$ & $38 \%$ & $36 \%$ & $48 \%$ \\
\hline Have participated, interested again & $10 \%$ & $27 \%$ & $3 \%$ & $18 \%$ \\
\hline $\begin{array}{l}\text { Have participated, not interested } \\
\text { again }\end{array}$ & $8 \%$ & $30 \%$ & $5 \%$ & $21 \%$ \\
\hline Number of respondents & 589 & & 1,348 & \\
\hline
\end{tabular}

${ }^{\mathrm{a}}$ Given that the median is reported for age and household income, the standard deviation is not reported. However, the mean age (standard deviation) and mean household income (standard deviation) for the total sample are $49.9(15.0)$ and $\$ 88,021(\$ 54,711)$, respectively, while the choice experiment sample mean age (standard deviation) and household income (standard deviation) are 48.0 (14.5) and $\$ 91,100(\$ 54,109)$, respectively.

${ }^{\mathrm{b}}$ The food neophobia scale is a ten-question scale with ratings from $1=$ "strongly disagree" to 7 = "strongly agree" as developed by Pliner and Hobden (1992). Higher scores imply increased food neophobia levels with a minimum score equal to ten and a maximum score of seventy. 
more likely to join a CSA include females (Lang 2005; Russell and Zepeda 2008), higher incomes (Brehm and Eisenhauer 2008, Russell and Zepeda 2008; Uribe, Winham, and Wharton 2012), Caucasian (Russell and Zepeda 2008; Uribe, Winham, and Wharton 2012) and older (Lang 2005; Uribe, Winham, and Wharton 2012).

Our sample's (including only those having participated in or having interest in joining a CSA) median income, median age, ethnic makeup, and percentage female were $\$ 85,000$, 48 years of age, 88 percent Caucasian, and 66 percent female, respectively. For comparison, the median household income for Connecticut was $\$ 70,331$, median age is 40 years of age, 81 percent Caucasian, and 51 percent female (U.S. Census Bureau 2016; U.S. Census Bureau 2017). Further providing some evidence that our sample is potentially representative, Russell and Zepeda (2008) and Uribe, Winham, and Wharton (2012) found household income of CSA participants at around $\$ 10,000$ above state levels and women participation at between 70-80 percent of their samples. In Uribe, Winham, and Wharton (2012), Caucasians made up over 90 percent of their sample of CSA users while Russell and Zepeda (2008) have a similar portion to the state. With respect to age, several studies have found the average CSA members age ranges between 40-50 years of age (Uribe, Winham, and Wharton 2012; Pole and Kumar 2015, Vasquez et al. 2017). Given that no exact CSA consumer or potential consumer can be defined, our sample appears to fit the profile of CSA consumer as defined by previous literature and is therefore generalizable outside of our sample. However, if the sample is not representative then the results are only generalizable within sample.

There are several caveats to our study; even though a large majority of the population (estimates range from 75-87 percent of U.S. households) used the Internet in 2013 (World Bank 2013; File and Ryan 2014), there are several potential disadvantages to using an online survey, notably that potential biases include lack or respondent engagement with answering survey questions (e.g., respondents clicking through the survey without reading the questions), self-selected respondents in an online convenience panel, and lack of responses from non-Internet users. We incorporated questions randomly throughout the survey, which had specific answers as noted in the question, to attempt to identify respondents who were not reading each question (i.e., not engaged). Exclusion of non-Internet users and self-selection in the convenience panel become an issue if non-Internet users have different attribute valuations than Internet users independent of demographics, which are included in the latent model. With the potential biases discussed above there is no way to test their impact on the results. Given this, all we can say is that our sample is made up of self-selected respondents with set demographic characteristics, and to the extent our sample represents CSA participants and potential participants we can make inferences that apply to the population of interest. 


\section{Survey and Choice Experiment}

The survey consisted of three parts: CSA usage question, choice experiment, and questions on purchasing behavior and demographics. The CSA usage question related to respondents' participation level and interest in joining a CSA, including: (1) currently participating in a CSA, (2) had previously participated (not currently) but have an interest in participating again, (3) had never participated but have an interest, (4) previously participated but do not have an interest in participating again, or (5) never participated and have no interest. Given that the focus of the paper is on consumers who have participated or have an interest in participating in a CSA, we limit the sample to respondents who currently are participating, have previously but are not currently participating, and respondents who have never participated but have an interest in joining a CSA.

Choice experiments elicit consumers' preferences for product attributes by asking consumers to select a CSA from a set of CSA alternatives. The elicited information allows for the estimation of a consumers' utility function and provides insights into their preferences for product attributes and price, as well as their WTP, defined as the price at which a consumer is indifferent between purchasing and not purchasing (Moorthy, Ratchford, and Talukdar 1997). In constructing the choice experiment, previous research (i.e., Connolly and Klaiber, 2014) had identified four attributes (i.e., product offerings, contract length, number of pick-up days, and production techniques) that can potentially affect the decision to join a CSA. For our choice experiment we also added price and the risk mitigation variable as attributes (Table 2).

Table 2. Attributes and Levels included within the Choice Experiment

\begin{tabular}{|c|c|c|c|c|c|}
\hline \multicolumn{6}{|c|}{ Attribute } \\
\hline Price & $\begin{array}{l}\text { Production } \\
\text { Practice }\end{array}$ & $\begin{array}{l}\text { Number } \\
\text { of Weeks }\end{array}$ & Pick-up Option & Product Type & Risk Mitigation \\
\hline$\$ 300$ & Organic & 8 & Once per week & Vegetables & $\begin{array}{l}\text { Discounted future } \\
\text { price }\end{array}$ \\
\hline$\$ 400$ & No label & 12 & Twice per week & $\begin{array}{l}\text { Fruit and } \\
\text { vegetables }\end{array}$ & $\begin{array}{l}\text { Money back for each } \\
\text { week no product }\end{array}$ \\
\hline$\$ 450$ & & 16 & $\begin{array}{l}\text { Drop off at central } \\
\text { location }\end{array}$ & Meat & $\begin{array}{l}\text { No money back or } \\
\text { discount }\end{array}$ \\
\hline$\$ 500$ & & & & $\begin{array}{l}\text { Vegetables and } \\
\text { meat }\end{array}$ & \\
\hline
\end{tabular}


The levels associated with price, number of weeks, production practices, types of products, and pick-up options were chosen based on values from a review of a majority of the CSAs in Connecticut conducted by the University of Connecticut Cooperative Extension (2012). With respect to the risk mitigation attribute, three levels were included: discount for a future order, money-back guarantee for the missed week, and no money back/discount. For example, if a respondent chose a CSA from the choice set that had a discount or money back as a part of the CSA bundle, then the respondent has the potential to either get a discounted rate on next year's CSA price or get the money back now for the time period(s) where no product was available. We did not specify an exact future discounted price.

After identifying the attributes and levels, the final choice design was established via the D-efficiency criterion which compares design efficiency with an orthogonal balanced design (Kuhfeld 2010). The final choice design consisted of 12 choice sets that were evaluated by each respondent. Within each choice set there were three CSA alternatives and a no purchase alternative. The attribute levels associated with each choice set was presented in text format, see Figure 1 for an example of a choice set. Both the choice sets and alternatives within each choice set were randomized in order to limit order bias. Before fielding the survey it was pretested by academic colleagues and graduate students within the department to ensure questions were worded appropriately.

Given that consumers are likely to be heterogeneous across tastes and preferences (Wedel and Kamakura 2000), we used a latent class model (LCM) to account for any unobserved heterogeneity (Wedel and Kamakura 2000; Boxall and Adamowicz 2002; Greene and Hensher 2003; Kafle, Swallow, and Smith 2014). The LCM model is similar to the mixed logit model; however, LCM relaxes the assumptions regarding the distribution of parameters across individuals that is imposed by the mixed logit model

\footnotetext{
Please evaluate the following CSA alternatives, and choose the alternative that you would like participate in.

$\$ 500$ for 8 weeks of organically produced meat with two days to pickup basket at CSA each week and no money back/discounted future price if basket is not available every week

$\$ 550$ for 8 weeks of organically produced fruit and vegetables with single day to pickup basket at CSA each week and money back for each week basket not available

$\$ 600$ for 12 weeks of vegetables and meat with single day to pickup basket at CSA each week and a discounted future price if basket not available every week

$\times$ None of the above
}

Figure 1. Example of Choice Set Evaluated by Survey Respondents. 
(Green and Hensher 2003). Assuming that consumer i's indirect utility function can be formulated as

$$
U_{i j \mid s}=X_{j} \beta_{s}+\varepsilon_{i j}
$$

where $X_{j}$ is a vector of product attributes $j, \beta_{s}$ is a class-specific vector of taste parameters, and $\varepsilon_{i j}$ is an error term that is i.i.d Type I extreme value distributed. Using the LCM we can estimate the unconditional probability that consumer $i$ is in class $s$ based on sociodemographic characteristics (equation 2).

$$
\operatorname{Prob}_{i s}=\frac{\exp \left(\theta_{s} Z_{i}\right)}{\sum_{s} \exp \left(\theta_{s} Z_{i}\right)}
$$

where $Z_{i}$ are sociodemographic characteristics for consumer $i$ and $\theta_{s}$ is a parameter vector that determines the class membership probability. Sociodemographic variables include those listed in Table 1, including household income, age, and ethnicity. We also include body mass index and a food neophobia scale. The food neophobia scale is a ten 10-question scale with ratings from 1 = "strongly disagree" to $7=$ "strongly agree" as developed by Pliner and Hobden (1992). Higher scores imply increased food neophobia levels with a minimum score equal to ten and a maximum score of seventy.

Equation 3 denotes the probability of consumer $i$ choosing product $j$ conditional on belonging to class $s$.

$$
\operatorname{Prob}_{i j \mid s}=\frac{\exp \left(\mu_{s} X_{j} \beta_{s}\right)}{\sum_{j} \exp \left(\mu_{s} X_{j} \beta_{s}\right)} .
$$

Within equation $3, \mu_{s}$ is the scale parameter for class $s$ and is normalized to 1. Equation 4 denotes the joint probability that product $j$ is chosen by consumer $i$ in class $s$.

$$
\operatorname{Prob}_{i j s}=\operatorname{Prob}_{i j \mid s}{ }^{*} \operatorname{Prob}_{i s}=\frac{\exp \left(\mu_{s} X_{j} \beta_{s}\right)}{\sum_{j} \exp \left(\mu_{s} X_{j} \beta_{s}\right)} * \frac{\exp \left(\theta_{s} Z_{i}\right)}{\sum_{s} \exp \left(\theta_{s} Z_{i}\right)} .
$$

The number of classes $(s)$ was determined by choosing the number of classes that minimized the Akaike Information Criteria (AIC). The final model used 500 Halton draws. The two-class model provided the lowest AIC and is used for the analysis and discussion below (Table 3). We employ an entropy method to test the robustness of our latent class model in assigning respondents to their latent class (Celeux and Soromenho 1996; Collins and 
Table 3. Selection Criterion for Number of Latent Classes

\begin{tabular}{ll}
\hline Number of Classes & AIC \\
\hline $1^{\mathrm{a}}$ & $17,310.1$ \\
2 & $17,303.4$ \\
3 & $17,378.5$ \\
4 & $17,427.7$ \\
\hline
\end{tabular}

${ }^{\mathrm{a}}$ AIC for a class model are from a multinomial logit model.

Lanza 2010). ${ }^{1}$ Using the parameter estimates from the LCM, we can define willingness to pay (WTP) for an attribute level as

$$
\mathrm{WTP}_{j}=-\frac{\beta_{j}}{\beta_{p}} .
$$

where $\beta_{j}$ is the coefficient of attribute $j$, and $\beta_{p}$ is the coefficient of the price attribute. Standard errors were calculated via the delta method.

\section{Results and Discussion}

The results from the LCM model are presented in Table 4. We find two heterogeneous classes that have varying CSA preferences and demographic probabilities. Latent class one encompasses 20 percent of respondents, while latent class two has 80 percent of respondents. As expected, the price coefficients are negative and significant, implying consumers value a lower price to a higher price. Further, similar to Connolly and Klaiber (2014), we find no differences associated with pick-up options. However, there are differences in preference between the latent classes for several of the other attributes. Furthermore, there are differences in the demographic variables associated with the probability of respondents being in each group.

\footnotetext{
1 As a robustness check we use the entropy methods described by Celeux and Soromenho (1996) and Collins and Lanza (2010) to evaluate the ability of our model to confidently put respondents into a class. Each method is bounded between 0 and 1 with $0=$ complete uncertainty over where to classify respondents and $1=$ complete certainty in classifying respondents into classes. The two methods give scores ranging from $0.6-0.8$, indicating that though we are not at the 0.8 "strong" confidence threshold for both methods, there is evidence that we can feel confident that our model is assigning respondents to the correct class.
} 
Table 4. Results of the Latent Class Model

\begin{tabular}{|c|c|c|c|c|}
\hline \multirow[b]{2}{*}{ Attribute } & \multicolumn{2}{|c|}{ Latent Class 1} & \multicolumn{2}{|c|}{ Latent Class 2} \\
\hline & Coefficient & p-value & Coefficient & p-value \\
\hline None & -0.243 & 0.510 & 0.223 & 0.100 \\
\hline Price & -0.003 & 0.000 & -0.004 & 0.000 \\
\hline \multicolumn{5}{|l|}{ Risk Incentive } \\
\hline No discount or money back & - & - & - & - \\
\hline Discounted future price & 0.472 & 0.001 & 0.584 & 0.000 \\
\hline Money back & 0.893 & 0.000 & 0.780 & 0.000 \\
\hline \multicolumn{5}{|l|}{ Organic } \\
\hline Organic: no & - & - & - & - \\
\hline Organic: yes & 0.124 & 0.290 & 0.321 & 0.000 \\
\hline \multicolumn{5}{|l|}{ Number of Weeks } \\
\hline 8 weeks & - & - & - & - \\
\hline 12 weeks & 0.278 & 0.081 & 0.721 & 0.000 \\
\hline 16 weeks & 0.388 & 0.034 & 1.010 & 0.000 \\
\hline \multicolumn{5}{|l|}{ Pick-up Options } \\
\hline Drop off & - & - & - & - \\
\hline 1-day pick-up & -0.004 & 0.974 & -0.034 & 0.518 \\
\hline 2-day pick-up & -0.028 & 0.835 & -0.059 & 0.310 \\
\hline \multicolumn{5}{|l|}{ Products Available } \\
\hline Vegetables & - & - & - & - \\
\hline Fruit and vegetables & 0.358 & 0.046 & 0.050 & 0.456 \\
\hline
\end{tabular}


Table 4. Continued

\begin{tabular}{|c|c|c|c|c|}
\hline \multirow[b]{2}{*}{ Attribute } & \multicolumn{2}{|c|}{ Latent Class 1} & \multicolumn{2}{|c|}{ Latent Class 2} \\
\hline & Coefficient & p-value & Coefficient & p-value \\
\hline Meat & 0.177 & 0.258 & -0.536 & 0.000 \\
\hline Vegetables and meat & 0.414 & 0.003 & 0.088 & 0.161 \\
\hline Variable & Coefficient & p-value & Coefficient & p-value \\
\hline Age & 3.039 & 0.000 & - & - \\
\hline \multicolumn{5}{|l|}{ Ethnicity } \\
\hline Caucasian & 1.624 & 0.224 & - & - \\
\hline African American & 1.282 & 0.489 & - & - \\
\hline Household income & 0.000 & 0.687 & - & - \\
\hline Gender $(1=$ male $)$ & 0.003 & 0.939 & - & - \\
\hline Body mass index (BMI) & -0.005 & 0.917 & - & - \\
\hline Food neophobia scale & -0.060 & 0.029 & - & - \\
\hline \multicolumn{5}{|l|}{ CSA Experience } \\
\hline Never participated, but interested & -1.496 & 0.076 & - & - \\
\hline Have participated, interested again & -0.649 & 0.505 & - & - \\
\hline Average class probabilities & 0.202 & & 0.798 & \\
\hline Log likelihood & -8617.720 & & & \\
\hline McFadden pseudo $\mathrm{R}^{2}$ & 0.1205 & & & \\
\hline $\operatorname{Prob}\left(\chi^{2}\right)$ & 0.000 & & & \\
\hline Number of choice observations & 7068 & & & \\
\hline Number of respondents & 589 & & & \\
\hline
\end{tabular}




\section{Latent Class One}

Examination of the coefficient associated with the "none" alternative indicates that latent class one does not gain or lose utility when choosing the "none" alternative. With respect to CSA attributes, consumers with a higher probability of being in latent class one value an increasing number of weeks for the CSA. This result is not unexpected, because a longer CSA season means the consumer is able to have access to the CSA products for a longer duration, thereby increasing the sense of getting more for their original share cost. We also find that consumers in this class value a discount on next year's CSA price and a money-back guarantee over no-risk guarantee. Given that we did not specify an exact discounted price, the respondents may have been thinking of differing amounts for a discount. Furthermore, we find that class one preferred fruit/vegetables as well as vegetables/meat to vegetables only. Interestingly, this class did not prefer organic production methods.

Given that class one has a smaller market share (only 20 percent), CSAs could be tempted to ignore this group in pursuit of class two (80 percent market share). Latent class one tends to be older, less food neophobic, and have been a member in a CSA before. From a marketing perspective, CSAs located near older consumers may want to focus on attributes preferred by latent class one. CSAs operating in an area with a lot of competition may be more likely to have experienced CSA consumers, who have been shown to indicate that lack of product mix can be a deterrent to rejoining a CSA (Cooley and Lass 1998; Perez, Allen, and Brown 2003; Lea et al. 2006). So when competing against other CSAs, especially for consumers with CSA experience, a CSA may want to have a broad product mix, because this latent class of consumers prefers fruit/vegetables and vegetables/meat compared to vegetables alone. Furthermore, this class tends to be less food neophobic. Given this class is less food neophobic, producers may want to offer different varieties or more unique products in their CSA baskets.

\section{Latent Class Two}

Examination of the coefficients associated with the "none" alternative indicates that latent class two receives a loss of utility when they choose the "none" alternative. Interestingly, this latent class is less likely to have participated in a CSA. Similar to latent class one, latent class two consumers value a longer CSA season and some sort of risk mitigation (discount or money back) when they do not receive their product every week (Table 4). This class also values organic production, while not wanting to have meat as one of the products available in their CSA basket. This class is more likely to be younger and have higher food neophobia than their class one counterparts.

In assessing a strategy that could work for targeting this class, CSAs should think about using online advertising methods, such as Facebook and Twitter, given that this class is more likely to be younger. Focusing on risk mitigation 
could be a means to convince this class to join the CSA, especially given their preference for risk mitigation and high probability of never having been a part of a CSA.

\section{Willingness to Pay}

Understanding preference is important, but from a CSA's perspective, understanding potential price premiums and/or discounts for various attributes is critical. With respect to the WTP estimates, we find that class one prefers but is not willing to pay more for a 12 -week season but is willing to pay $\$ 111$ for a 16 -week season over the 8-week season price (Table 5). However, class two is willing to pay $\$ 180$ and $\$ 252$ over the 8-week season for 12 and 16 weeks, respectively. With respect to the different magnitudes it is most likely the CSA variable driving the results as class one is made up of more respondents who have tried a CSA and may have some knowledge that a greater number of weeks is not as valuable to them. Notably, it has been shown that providing too much produce can be an issue for CSA members, given the member now has to find out what to do with the extra produce (Cooley and Lass 1998; Perez, Allen, and Brown 2003). If this is the case, then someone with CSA experience may want a greater number of weeks but be willing to pay less for the longer season. Furthermore, Connolly and Klaiber (2014) find an overall CSA premium of 2.5 percent for an extra week, which is comparable, but slightly below the approximate 5 percent per-week premium we find.

With respect to organic, class two is willing to pay an 18 percent premium over the average $\$ 467$ CSA price in Connecticut. However, the premium is only for class two, because class one is not willing to pay for organic compared to nonorganic food. The average organic premium found by Connolly and Klaiber (2014) is 7 percent, but the premium varied considerably by state. Notably, Pennsylvania and Ohio had a premium around 12 percent (Connolly and Klaiber 2014). Given their proximity to Connecticut this finding does validate, to a degree, the organic premium we find in our study.

With respect to the risk mitigation attribute, class one is willing to pay a $\$ 135$ premium for a future year discount. Class two is willing to pay $\$ 146$ for the same discount. This represents around a 30 percent premium across classes for the future year discount. However, class two is willing to pay $\$ 256$ for a money-back guarantee, while class one will pay on average $\$ 194$. This represents a 55 percent and 42 percent premium for class one and two over the average CSA price of $\$ 467$, respectively. Though the future year discount and money-back guarantee are different types of risk-mitigation methods than those looked at by Sproul, Kropp, and Barr (2015), the premiums we find are similar in magnitude to the 38 percent premium they found for a weighted share. However, CSA managers need to understand the WTP estimates are provided with 95 percent confidence intervals that bracket expected premiums consumers would pay. For instance, we are fairly 
Table 5. Willingness to Pay for CSA Attributes

\begin{tabular}{|c|c|c|c|c|c|c|c|c|}
\hline \multirow[b]{3}{*}{ Attribute } & \multicolumn{4}{|c|}{ Latent Class 1} & \multicolumn{4}{|c|}{ Latent Class 2} \\
\hline & \multirow[b]{2}{*}{ WTP } & \multirow[b]{2}{*}{ p-value } & \multicolumn{2}{|c|}{$\begin{array}{l}95 \text { percent Confidence } \\
\text { Interval }\end{array}$} & \multirow[b]{2}{*}{ WTP } & \multirow[b]{2}{*}{ p-value } & \multicolumn{2}{|c|}{$\begin{array}{l}95 \text { percent Confidence } \\
\text { Interval }\end{array}$} \\
\hline & & & Lower Bound & Upper Bound & & & Lower Bound & Upper Bound \\
\hline \multicolumn{9}{|l|}{ Risk Incentive } \\
\hline Discount & $\$ 135.28$ & 0.005 & $\$ 41.26$ & $\$ 229.31$ & $\$ 145.61$ & 0.000 & $\$ 112.71$ & $\$ 178.51$ \\
\hline Money back & $\$ 255.91$ & 0.000 & $\$ 155.63$ & $\$ 356.19$ & $\$ 194.33$ & 0.000 & $\$ 158.30$ & $\$ 230.35$ \\
\hline \multicolumn{9}{|l|}{ Organic } \\
\hline Organic: yes & $\$ 35.40$ & 0.270 & $-\$ 27.54$ & $\$ 98.34$ & $\$ 79.97$ & 0.000 & $\$ 56.07$ & $\$ 103.88$ \\
\hline \multicolumn{9}{|l|}{ Number Weeks } \\
\hline 12 weeks & $\$ 79.51$ & 0.101 & $-\$ 15.53$ & $\$ 174.56$ & $\$ 179.68$ & 0.000 & $\$ 142.11$ & $\$ 217.25$ \\
\hline 16 weeks & $\$ 111.28$ & 0.059 & $-\$ 4.30$ & $\$ 226.86$ & $\$ 251.82$ & 0.000 & $\$ 210.59$ & $\$ 293.06$ \\
\hline \multicolumn{9}{|l|}{ Pick-up Options } \\
\hline 1-day pick-up & $-\$ 1.14$ & 0.974 & $-\$ 70.37$ & $\$ 68.10$ & $-\$ 8.50$ & 0.517 & $-\$ 34.23$ & $\$ 17.23$ \\
\hline 2-day pick-up & $-\$ 7.98$ & 0.835 & $-\$ 82.85$ & $\$ 66.89$ & $-\$ 14.60$ & 0.304 & $-\$ 42.40$ & $\$ 13.21$ \\
\hline \multicolumn{9}{|l|}{ Products Available } \\
\hline Fruit and vegetables & $\$ 102.61$ & 0.065 & $-\$ 6.48$ & $\$ 211.69$ & $\$ 12.40$ & 0.458 & $-\$ 20.35$ & $\$ 45.15$ \\
\hline Meat & $\$ 50.83$ & 0.272 & $-\$ 39.77$ & $\$ 141.43$ & $-\$ 133.72$ & 0.000 & $-\$ 170.20$ & $-\$ 97.24$ \\
\hline Vegetables and meat & $\$ 118.71$ & 0.011 & $\$ 27.13$ & $\$ 210.29$ & $\$ 21.95$ & 0.167 & $-\$ 9.19$ & $\$ 53.09$ \\
\hline
\end{tabular}


confident that class one could would pay between $\$ 41$ and $\$ 229$ for a discount and $\$ 156$ to $\$ 356$ for money back.

The choice of whether or not to offer a guarantee or discount should be based on both potential cost to the CSA and type of consumer owning a share in the CSA. For example, assuming a $\$ 467$ cost per whole share (choice set average value) and the mean WTP ( $\$ 256$ for a class one consumer) when offering a money-back guarantee would be $\$ 723$ which equates to $\$ 90$ per week over an eight week season. So if a money back guarantee were offered and one week of money had to be returned then the producer would still gain $\$ 166$ (\$723-\$90-\$467) over the \$467 that would have been charged without the guarantee. Calculating the breakeven point shows that a producer would still be almost equivalent in dollar terms at three weeks of compensating the consumer for lost product. Based on these estimates, it is worth providing a money back guarantee that targets class one if the producer expects three weeks or less or poor harvest. The premiums for class two make offering a risk guarantee a little less viable. Assuming an 8-week season, the average revenue per week when including a money-back guarantee would be $\$ 81$, which implies that the CSA would suffer losses if more than two weeks required money to be repaid. However, if a CSA manager charges a lower premium, say the money back guarantee lower confidence interval value for latent class two, the season share price would be $\$ 580$ with two weeks of money back being the equilibrium.

We find no significant premiums/discounts for pick-up options. From a producer standpoint, the costs associated with increasing the number of pickup days or offering a drop-off option should be weighed with the fact consumers will not want to pay a premium for these extra benefits. Further, class two shows a negative WTP $(-\$ 134)$ for meat options compared to vegetable-only CSAs. However, class one shows a positive premium for fruit and meat in the CSA basket that also included vegetables. There are several potential reasons for these differences. For instance, class one respondents were more likely to have experience with a CSA, and they view meat in addition to vegetables as an enhancement to their share. However, class two is not experienced with a CSA, and may perceive vegetables as the primary component to their share, thereby devaluing meat.

\section{Conclusions}

The number of CSAs in the United States is continuing to increase. As the CSA market approaches a saturation point, it will be imperative for producers to identify and target select customers. In order to do this, producers need to understand what consumers value in a CSA while understanding that consumers are heterogeneous. Assuming that consumers are homogeneous could potentially cause CSAs to target their CSA to the wrong consumer group or stress the importance of the wrong attributes. This paper helps fill 
in this gap by identifying preference and WTP for common CSA attributes as well as a risk-mitigation attribute.

We find heterogeneous preferences for CSA attributes in our sample. To the extent our sample is representative of Connecticut CSA (potential) consumers, we can generalize to this population of consumers. Notably, not all consumers value organic production, similar to Connolly and Klaiber (2014). Younger consumers are more likely to value organic production, which implies CSAs located in areas with a younger population may benefit from considering organic production instead of conventional production. However, both latent classes value all types of risk mitigation presented in the experiment. Even though consumers seem to be willing to pay a price premium for a risk mitigation attribute, it does not imply that it should be offered to increase revenues. In "good" years when a product can be provided every week, then the CSA stands to gain extra income; however, in years when product is not provided every week, there is the potential for the CSA to lose money. Thereby, implementation of a risk-mitigation attribute should be evaluated based on past history of providing product as well as potential revenues associated with a higher price as well as how the risk attribute will be seen by the CSAs' current and future clientele.

With respect to how our findings compare to previous work, our results are somewhat comparable to those of Connolly and Klaiber (2014). Both papers find number of weeks having a positive effect on preference. For organic, both papers find heterogeneity with Connolly and Klaiber (2014) at the state level and this paper at the within-state consumer level. Of interest, we find an 18 percent premium for organic (at the \$450) for latent class two, similar to that found by Connolly and Klaiber (2014). Based on the similarities of these findings, CSAs could potentially increase their share prices by 10-15 percent if they are in areas that value organic production.

\section{References}

Boxall, P.C., and W. Adamowicz. 2002. "Understanding Heterogeneous Preference in Random Utility Model: A Latent Class Approach." Environmental and Resource Economics 23(4): 421-446.

Brehm, J.M., and B.W. Eisenhauer. 2008. "Motivations for Participating in CommunitySupported Agriculture and Their Relationship with Community Attachment and Social Capital." Southern Rural Sociology 23(1): 94-115.

Brown, C., and S. Miller. 2008. "The Impacts of Local Markets: A Review of Research on Farmers Markets and Community Supported Agriculture (CSA)." American Journal of Agricultural Economics 90(5): 1296-1302.

Celeux, G., and G. Soromenho. 1996. "An Entropy Criterion for Assessing the Number of Clusters in a Mixture Model." Journal of Classification 13(2): 195-212.

Collins, L., and S. Lanza. 2010. Latent Class and Latent Transition Analysis: With Applications in the Social, Behavioral, and Health Sciences. New York: Wiley.

Connecticut Governor's Council for Agricultural Development. 2016. "An Act Concerning the Governor's Council for Agricultural Development." Substitute House Bill No. 5508, Public 
Act No. 11-189. Available at http://www.ct.gov/doag/cwp/view.asp?a=1367\&q=423842 (accessed 15 March 2017).

Conner, D.S. 2003. "Community Supported Agriculture Pricing and Promotion Strategies: Lessons from Two Ithaca, NY Area Farms." College of Agriculture and Life Sciences, Cornell University. Available at http://ageconsearch.umn.edu/bitstream/122132/2/ Cornell_AEM_eb0307.pdf (accessed 15 April 2017).

Connolly, C., and H.A. Klaiber. 2014. "Does Organic Command a Premium When the Food is Already Local?" American Journal of Agricultural Economics 96(4): 1102-1116.

Cooley, J.P., and D.A. Lass. 1998. "Consumer Benefits from Community Supported Agriculture Membership." Review of Agricultural Economics 20(1): 227-237.

Ernst, M. "Community Supported Agriculture." 2013. University of Kentucky Cooperative Extension Service, Center for Crop Diversification Marketing Profile. Available at https://www.uky.edu/Ag/CCD/marketing/csa.pdf (accessed 30 March 2017).

File, T., and C. Ryan. 2014. "Computer and Internet Use in the United States: 2013." United States Census Bureau - American Community Survey Reports (2014):ACS-28. Available at http://www.census.gov/content/dam/Census/library/publications/2014/ acs/acs-28.pdf (accessed 06 March 2017).

Goland, C. 2002. "Community Supported Agriculture, Food Consumption Patterns, and Member Commitment." Culture and Agriculture 24(1): 14-25.

Greene, W.H., and D.A. Hensher. 2003. "A Latent Class Model for Discrete Choice Analysis: Contrasts with Mixed Logit." Transportation Research B 37(8): 681-698.

Kafle, A., S. Swallow, and E. Smith. 2014. "Does Public Funding Affect Preferred Tradeoffs and Crowd-in or Crowd-out Willingness to Pay? A Watershed Management Case." Environmental and Resource Economics 60(3): 471-95.

Kelley, K.M., L.F. Kime, and J.K. Harper. "Community Supported Agriculture (CSA)." Penn State Extension. 2013. Available at http://extension.psu.edu/business/ag-alternatives/marketing/ community-supported-agriculture-csa/extension_publication_file (accessed 5 March 2017).

Kuhfeld, W.F. 2010 "The Macros." In Marketing Research Methods in SAS. Technical Paper MR2010, SAS Institute Inc., Cary, NC. Available at https://support.sas.com/techsup/ technote/mr2010.pdf (accessed 10 January 2017).

Kolodinsky, J.M., and L.L. Pelch. 1997. "Factors Influencing the Decision to Join a Community Supported Agriculture (CSA) Farm." Journal of Sustainable Agriculture 10(2-3): 129-141.

Lang, K.B. 2005. "Expanding Our Understanding of Community Supported Agriculture (CSA): An Examination of Member Satisfaction." Journal of Sustainable Agriculture 26(2): 61-79.

Lass, D., A. Bevis, G.W. Stevenson, J. Hendrickson, and K. Ruhf. 2003. "Community Supported Agriculture Entering the $21^{\text {st }}$ Century: Results from the 2001 National Survey." Amherst: University of Massachusetts, Department of Resource Economics. Available at http:// www.cias.wisc.edu/wp-content/uploads/2008/07/csa_survey_01.pdf (accessed 19 March 2017).

Lea, E., J. Phillips, M. Ward, and A. Worsley. 2006. “Farmers' and Consumers' Beliefs About Community Supported Agriculture in Australia: A Qualitative Study." Ecology of Food and Nutrition 45(2): 61-86.

Lizio, W., and D.A. Lass. 2005. CSA 2001: An Evolving Platform for Ecological and Economical Agricultural Marketing and Production. Amherst: Department of Resource Economics, University of Massachusetts. Available at http://api.ning.com/files/3FyohVhrKm5eIn2G2jfkF2vpDUXaYlfQtSpRUvy4u2WE1tMaovZ673Tnfo*fd8T3ysBa9ncJb4Z81p TNEIQUaoTvYJIe6Qs/NESAWGCSA2001.pdf (accessed 10 March 2016).

LocalHarvest, Inc. 2016. "LocalHarvest."Available at http://www.localharvest.org (accessed 25 March 2017).

Low, S.A., A. Adalja, E. Beaulieu, N. Key, S. Martinez, A. Melton, A. Perez, K. Ralston, H. Stewart, S. Suttles, and S. Vogel. 2015. "Trends in U.S. Local and Regional Food Systems: A Report to Congress." USDA-ERS Economic Research Report 2015(068). Available at https:// 
www.ers.usda.gov/webdocs/publications/42805/51173_ap068.pdf?v=42083 (accessed 12 March 2017).

Low, S.A., and S.J. Vogel. 2011. "Direct and Intermediated Marketing of Local Foods in the United States." USDA-ERS Economic Research Report 2011(128). Available at https:// www.ers.usda.gov/webdocs/publications/44924/8276_err128_2_.pdf?v=41056 (accessed 12 March 2017).

McFadden, S. 2012. "Unraveling the CSA Number Conundrum." The Call of the Land: An Agrarian Primer for the 21st Century. Available at https://thecalloftheland.wordpress. com/2012/01/09/unraveling-the-csa-number-conundrum/ (accessed 30 March 2016).

Moorthy, S., B.T. Ratchford, and D. Talukdar. 1997. "Consumer Information Search Revisited: Theory and Empirical Analysis." Journal of Consumer Research 23(4): 263-277.

O'Hara, S.U., and S. Stagl. 2001. "Global Food Markets and Their Local Alternatives: A SocioEcological Economic Perspective." Population and Environment 22(6): 533-554.

Onozaka, Y., G. Nurse, and D.D. McFadden. 2010. "Local Food Consumers: How Motivations and Perceptions Translate to Buying Behavior." Choices 25(1):np.

Ostrom, M.R. 2007. “Community Supported Agriculture as an Agent of Change: Is it Working? In C.C. Hinrichs and T.A. Lyson, eds., Remaking the North American Food System: Strategies for Sustainability. Lincoln, NE: University of Nebraska Press, pp. 99-120.

Perez, J., P. Allen, and M. Brown. 2003. "Community Supported Agriculture on the Central Coast: The CSA Member Experience." The Center for Agroecology and Sustainable Food Systems, Research Brief \#1. Available at: https://escholarship.org/content/qt5wh3z9jg/ qt5wh3z9jg.pdf (accessed 5 October 2017).

Pliner, P. and K. Hobden. 1992. "Development of a Scale to Measure the Trait of Food Neophobia in Humans." Appetite 19(2): 105-120.

Pole, A., and A. Kumar. 2015. "Segmenting CSA Members by Motivation: Anything but Two Peas in a Pod." British Food Journal 117(5): 1488-1505.

Russell, W.S., and L. Zepeda. 2008. "The Adaptive Consumer: Shifting Attitudes, Behaviour Change and CSA Membership Renewal." Renewable Agriculture and Food Systems 23 (2): 136-148.

Sproul, T.W., and J.D. Kropp. 2015. "A General Equilibrium Theory of Contracts in Community Supported Agriculture." American Journal of Agricultural Economics 97(5): 1345-1359.

Sproul, T.W., J.D. Kropp, and K.D. Barr. 2015. "The Pricing of Community Supported Agriculture Shares: Evidence from New England." Agricultural Finance Review 75(3): 313-329.

Strochlic, R., and C. Shelley. 2004. Community Supported Agriculture in California, Oregon, and Washington: Challenges and Opportunities. Davis, CA: California Institute for Rural Studies.

United States Census Bureau. 2016. "2011-2015 American Community Survey 5-Year Estimates." Available at https://factfinder.census.gov/faces/tableservices/jsf/pages/ productview.xhtml?src=CF (accessed 10 October 2017).

_. 2017. "Quickfacts: Connecticut." Available at https://www.census.gov/quickfacts/ table/PST045215/00,09 (accessed 24 March 2017).

University of Connecticut Cooperative Extension. 2012. "Tools for CSA Farms Prepared for: CSA School-By Farmers, For Farmers November 28, 2012. Available at http://www. extension.uconn.edu/documents/CSA_School_Booklet_112812_001.pdf (accessed 15 January 2017).

Uribe, A.L.M., D.M. Winham, and C.M. Wharton. 2012. "Community Supported Agriculture Membership in Arizona. An Exploratory Study of Food and Sustainability Behaviours." Appetite 59(2): 431-436.

Vasquez, A., N.E. Sherwood, N. Larson, and M. Story. 2017. "Community-Supported Agriculture as A Dietary and Health Improvement Strategy: A Narrative Review." Journal of the Academy of Nutrition and Dietetics 117(1): 83-94. 
Wedel, M., and W.A. Kamakura. 2000. Market Segmentation: Concepts and Methodological Foundations. Boston: Kluwer Academic Publishers.

Wilkinson, J. 2001. “Community Supported Agriculture.” OCD Technote 20:1-2.

World Bank. 2013. "Internet Users (Per 100 People).” Available at http://data.worldbank.org/ indicator/IT.NET.USER.P2 (accessed 9 February 2014).

Zepeda, L., A. Reznickova, and W.S. Russell. 2013. "CSA Membership and Psychological Needs Fulfillment: An Application of Self-Determination Theory.” 30(4): 605-614. 